\section{EXPECT: A PASCAL program for calculating expected values in ANOVA models}

\section{CALVIN D. SOWDER}

California State University, Chico, California 95929

EXPECT calculates expected values for factorial ANOVA models with 10 or fewer factors. It implements rules presented in Millman and Glass (1967). The program accommodates models with fixed, random, nested, and crossed factors. Users need only be familiar with these types of factors to use EXPECT. The program should be useful both to experimenters during the design phase of their research and to students in a first course in experimental design.

Input. The program is interactive, and the user must answer, via a terminal, questions concerning: (1) number of factors, (2) the name for each factor, (3) the number of levels for each factor, (4) whether each factor is random or fixed, and (5) information about nesting.

Output. Output consists of a listing to the terminal of all variance sources, their degrees of freedom, and expected value terms for each variance source. A summary of input data is also listed.

Language and Computer. EXPECT was written in PASCAL using a PDP-11/70. The version of PASCAL used is OMSI-2. Few modifications (if any) should be necessary for use on other machines.

Availability. Listings may be obtained, free of charge, from Calvin Sowder, Department of Psychology-234, California State University, Chico, California 95929.

\section{REFERENCE}

Millman, J., \& Glass, G. V. Rules of thumb for writing the ANOVA table. Journal of Educational Measurement, 1967, 4, 41-51.

(Accepted for publication August 24, 1982.) 